BOOK REVIEW

Dieter Voth

\title{
Y. Yonekawa, Y. Sakurai, E. Keller, T. Tsukahara (eds): New trends in cerebral aneurysm management. (Acta Neurochirurgica, Supplementum 82)
}

\author{
Springer, Vienna New York, 2002. 121 pp with figures (ISBN 3-211-83751-5) EUR 76.00
}

Published online: 29 March 2003

(C) Springer-Verlag 2003

This relatively short, well appointed volume compiles 19 contributions, 11 of which concern therapy planning for nonruptured aneurysms and eight with the treatment of ruptured aneurysms and subarachnoid bleeding. It includes the presentations at a convention of German, Swiss, and Japanese specialists held in May 2001 in Zürich, Switzerland. Of the chapters, nine were provided by Japanese participants, seven were from Switzerland, two came from Germany, and one was from a Finnish author.
Drawing on single and variously extensive studies, the contributions deal with problems in the treatment of nonruptured aneurysms by demonstrating the results in operative procedures, wall reinforcement of the aneurysms, and possibilities allowed by endovascular methods. The indications for these techniques are clear and meet with universal agreement. In all, this report less describes new and future directions but more describes clearly the present state of the art, thus making this work of interest to all neurosurgeons. 